\title{
The First Human Immunotherapy Trial with a Viral Oncolysate Vaccine Induced a Large Number of Granular Lymphocytes Later Recognized as 'Natural Killer Cells'
}

Joseph G Sinkovics*

Department of Molecular Medicine, Cancer Institute, St. Joseph's Hospital, Morsani College of Medicine, The University of South Florida, Tampa, Florida, USA

*Corresponding author: Joseph G Sinkovics, Cancer Institute, St. Joseph's Hospital, Tampa, Florida, USA Joseph G Sinkovics, Cancer Institute, St. Joseph's Hospital, Tampa, Florida, USA

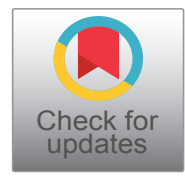

\section{In General}

The first visualization (and photographic records) of what has become known much later as human "natural killer cells" (NK) was initiated in 1969 at the Section of Clinical Tumor Virology and Immunology, Department of Medicine, The University of Texas M.D. Anderson Hospital, Houston TX [1]. A clinical hematopathologist suggested that those cells were monocyte-like (M); another viewed them as 'unusual lymphoblasts'. The cells in question were much larger than the already known cytotoxic T lymphocytes. Autologous or allogeneic human tumor cells (first sarcoma cells; later melanoma cells; later adenocarcinoma cells) with small compact $T$ lymphocytes attached to them, died mainly with nuclear clumping (later discovered elsewhere as "apoptosis"); some tumor cells died in cytoplasmic lysis. Whereas, the dominant form of target cell death was cytoplasmic lysis upon the attachment of the large granular lymphoid cells. Upon contact with autologous or allogeneic tumor cells, the large granular lymphoid cells released minuscule cytoplasmic granules that penetrated and lysed the target tumor cells by piercing through their cytoplasm. The control buffy coat lymphocytes were provided by the healthy donor (the author of this article, JGS). The very first patient yielded chondrosarcoma cells from his tumor, and immune $T$ cells from his circulating blood $[2,3]$. The healthy donor's small compact T lymphocytes practiced emperipolesis but without inducing tumor cell death; instead, out of the healthy donor's buffy coat preparations, large granular lymphoid cells appeared that attached to the allogeneic tumor cells and lysed them [4]. Buffy coat samples of tumor-bearing patients also yielded the cytotoxic large granular lymphoid cells, but healthy donors did not possess the small compact specifically tumor-immune $\mathrm{T}$ lymphocytes. This author (JGS) was working on $\mathrm{NIH} / \mathrm{NCl}$ Contracts and Awards (5-K3-CA-1647; NIH 71-2178; 1-CP3-3292). NIH/NCI project site visitors declared that "phenomena of in vitro artifacts" due to questionable chemical impurities are generated in the author's chamber slide culture vessels, because without pre-immunization no specific immune reactions were possible. Or, that the author in his professional service was exposed to an as yet undiscovered human cancer (sarcoma) retrovirus, inasmuch that these viruses were widely spread in the animal world (fish; birds; mammalians: mice; monkeys). Or, that the author (JGS) experienced a sarcoma that he has unknowingly rejected in its earliest stage, thus gaining immunity. Then the author showed that his large granular lymphoid cells reacted with and killed in vitro gynecologic carcinoma cells. The blood of the laboratory technicians also yielded the cytotoxic large granular lymphoid cells. At this point, two representatives of the $\mathrm{NIH} / \mathrm{NCl}$ requested the temporary transfer of "their contract" (including the author's contract-paid associate $\mathrm{H}$ David Kay PhD), and our human tumor cell lines, to the $\mathrm{NIH} / \mathrm{NCl}$ intramural laboratories for the study of the 'in vitro artifact phenomenon', especially if it were reproducible in radioactive label release assays readi-

Citation: Sinkovics JG (2019) The First Human Immunotherapy Trial with a Viral Oncolysate Vaccine Induced a Large Number of Granular Lymphocytes Later Recognized as 'Natural Killer Cells'. Int J Virol AIDS 6:049. doi.org/10.23937/2469-567X/1510049

Accepted: March 14, 2019: Published: March 16, 2019

Copyright: (C) 2019 Sinkovics JG. This is an open-access article distributed under the terms of the Creative Commons Attribution License, which permits unrestricted use, distribution, and reproduction in any medium, provided the original author and source are credited. 
ly available there (but not in the Sinkovics Lab). There, $\mathrm{NCl}$ investigators soon claimed the discovery of natural killer (NK) cells, first murine then human. A few years later (1975), a tumor virology laboratory of the highest reputation in Stockholm Sweden reported the belated discovery of a new set of 'NK cells' in the spleens of mice, specifically reactive to Moloney virally-induced mouse leukemia cells (not a faculty of genuine NK cells). By now, it has been widely accepted that the primordial urochordates Botryllus possess the ancestors of all NK cells, which are operational without pre-immunization in the entire population of hosts upward to Homo in the evolutionary scale [4-7].

\section{In Specifics}

In the early-to-mid-1970s a protocol for the combined chemo-immunotherapy of adult patients with various metastatic sarcomas was designed, submitted, Surveillance Committee-approved, and carried out to its early conclusion at the Department of Medicine, The University of Texas M.D. Anderson Hospital, Houston TX. The protocol consisted of doxorubicin-based chemotherapy at four-weeks intervals with scarified BCG without (19 patients in Group \#2), or with (19 patients in Group \#3) live PR8 influenza viral oncolysate (VO) vaccinations given to non-randomized adult patients. In Group \#1, 49 patients served as controls receiving only standard doxorubicin-based chemotherapy. In vitro assays checked the patients' immune reactivity to cultured autologous (whenever available) [7], or allogeneic cultured sarcoma cells. In the $6^{\text {th }}$ month, $72 \%$ of the control Group \#1 patients progressed to moribund state, including the deaths of 17 patients: $36(17) / 49$. At the same time, $53 \%$ of Group \#2 patients progressed including 4 deaths: 10(4)/19. In Group \#3, $32 \%$ of the patients progressed, 3 terminating in deaths: $6(3) / 19[8,9]$. In vitro tumor cell deaths in chamber/slide cultures revealed extraordinary observations. Taken from the patients' blood buffy coats, compact small round $T$ lymphocytes attacked and lysed autologous or allogeneic sarcoma target cells. These cytotoxic T lymphocytes were detectable both in patients in remission, or in advanced stages.

In vitro tumor cell deaths were due to 'nuclear clumping' (later discovered elsewhere as 'apoptosis'). The healthy author's (JGS) buffy coat lymphocytes were used as 'negative control'. In these cultures, instead of the small compact $T$ lymphocytes, unexpectedly, the
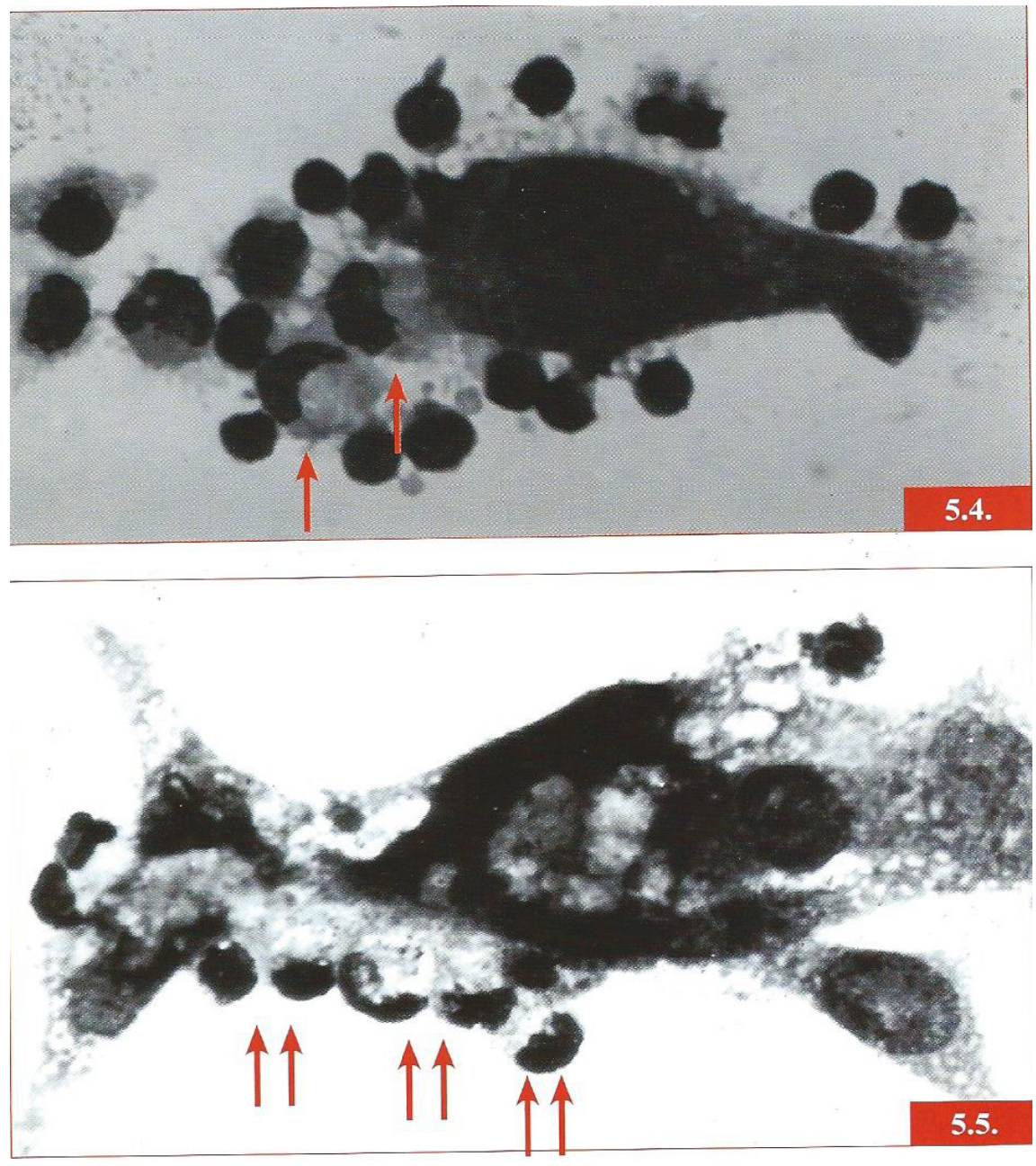

Figure 1: Figures 5.4 5.5. Early photographs of historical value taken in 1969 to show the attachment of small compact $T$ lymphocytes and the newly discovered large granular lymphoid cells to autologous tumor cells (1969) [1]. Reproduction by Schenk Buchverlag [4]. 
newly observed large granular lymphoid cells emerged and killed the allogeneic tumor cells by releasing tiny oncolytic granules (Figure 1, Figure 2 and Figure 3) [1,1012]. The $\mathrm{NIH} / \mathrm{NCl}$ project site visitors declared that this latter event was due to an "in vitro artifact" phenomenon occurring inadvertently in the chamber slide culture vessels. That 'presumption' never was documented. By visual scannings, the number of reactive large granular
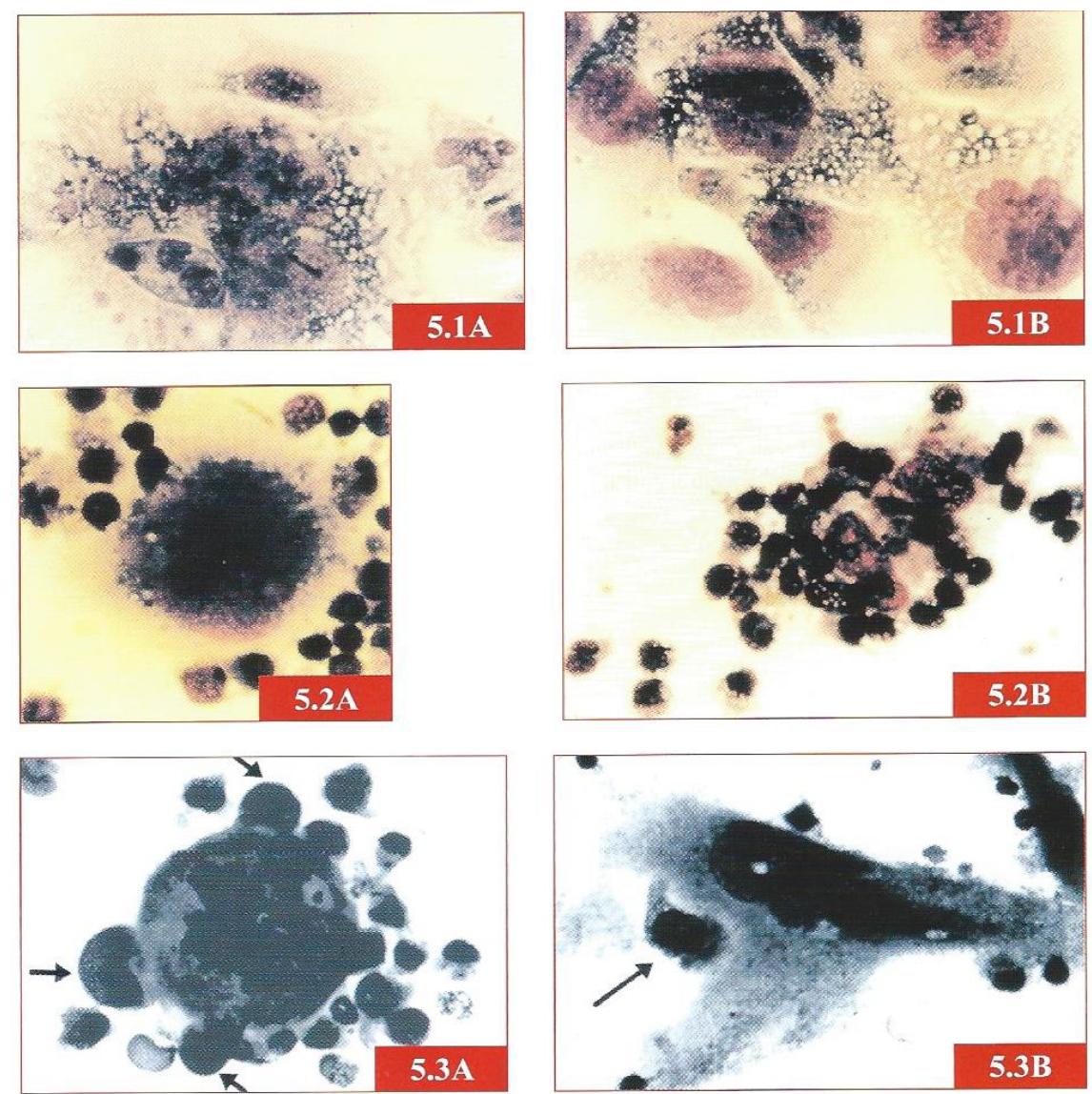

Figure 2: Figures 5.1A-5.3B. Patient with chondrosarcoma mobilizes small compact T lymphocytes to destroy his autologous tumor cells (colored pictures). Normal control (JGS) T lymphocytes practice emperipolesis but do not attack; large granular lymphoid cells (arrows) firmly attach and eventually lyse target tumor cells (B\&W pictures). One the first pictures of human NK cells in the literature (1969) [4]. Reproduced in [3].

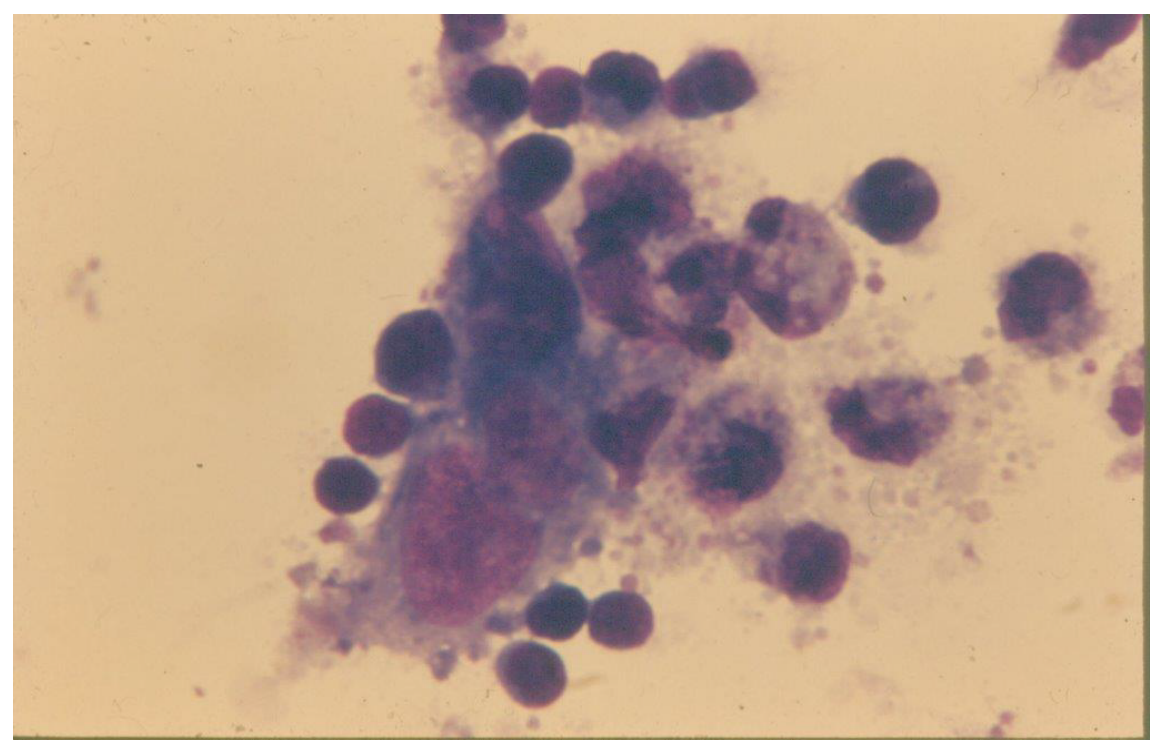

Figure 3: Figure of target sarcoma cell attacked by small compact immune T cells and large granular NK cells releasing minuscule granules to penetrate and lyse the cell membrane of the target sarcoma cell. Donor patient LN \#90641 with metastatic liposarcoma in remission was immunized with PR8 viral oncolysate vaccine prepared from the targeted sarcoma cells (presented patient in Sinkovics, Plager, Papadopoulos, et al. MD Anderson Hospital, Year Book Medical Publisher $1977 ; 267-288)$ [15,16]. Reproduced by Schenk Buchverlag [4]. 
lymphoid cells was the highest in the specimens of the Group 3 patients. Thus was the discovery of the genuine human NK cells transferred from its original location to the $\mathrm{NIH} / \mathrm{NCl}[10]$; the original illustrations remain preserved [4,11-13]. Yet the distinguished academic medical historian Marshall Lichtman continues to reveal the true story [14].

Major involvement in the original work was by medical technologists: Jerry Cabiness and Jim J Romero; basic scientists: H David Kay PhD, Dieter Gröschel $M D$, Eichi Shirato MD, Harikishan Thota PhD; surgical oncologists Martin RG, White ER; clinician medical oncologists-hematologists: Nicolas Papadopoulos MD, Carl Plager MD; and the responsible designer of the clinical trial: Joseph G. Sinkovics MD; department head supervisors: Clifton D Howe, C Charles Shullenberger; Nursing and Pharmacology Staff, MD Anderson Hospital, Houston TX.

\section{Acknowledgement}

The grants \& contracts for the time period involved were C-6529 CA-7923 NCl-NO-33292 NIH-71-2178 1-CP3-3292. (There are some more: C-4887 and Award 5-K3CA-1647).

\section{References}

1. Sinkovics JG, Shirato E, Gyorkey F, Cabiness JR, Howe CD (1970) Relationship between lymphoid neoplasms and immunologic functions. In "Leukemia-Lymphoma", MD Anderson Hospital Symposium 1969. Yearbook Medical Publisher Chicago IL 53-92.

2. Sinkovics JG, Shirato E, Martin RG, Cabiness JR, White ED (1971) Chondrosarcoma II. Immune reactions of a patient to autologous tumor. Cancer 27: 782-793.

3. Sinkovics JG (2004) Human chondrosarcoma cell differentiation. Pathology Oncology Research 10: 174-187.

4. Sinkovics JG (2008) Cytolytic Immune Lymphocytes in the Armamentarium of the Human Host. Buchverlag Schenk, Passau/Budapest.
5. Kay HD, Sinkovics JG (1974) Cytotoxic lymphocytes from normal donors. Lancet 2: 296-297.

6. Sinkovics JG, Horvath JC (2008) Natural and genetically engineered viral agents for oncolysis and gene therapy of human cancers. Arch Immunol Ther Exp (Warsz) 56: S3S59.

7. Sinkovics JG (2008) Adoptive immunotherapy for human cancers. In: M Kiselevskiy, Effectors in Antitumor Immunity. N Blokhin Cancer Center Moscow Russia. Springer Verlag, 1-23.

8. Sinkovics JG, Plager C, Romero JJ (1977) Immunology and immunotherapy of patients with sarcomas. In: R Crispen, University of Chicago Symposium: Immunotherapy of Solid Tumors. Franklin Institute Press, Philadelphia, 211-219.

9. Sinkovics JG, Horvath JC (2006) Evidence accumulating in support of cancer vaccines combined with chemotherapy. Int J Oncol 29: 765-777.

10. Sinkovics JG, Horvath JC (2005) Human NK cells: A comprehensive review. Int J Oncol 27: 5-47.

11. Sinkovics JG (1986) Cytotoxic lymphocytes. Ann Clin Lab Sci 16: 488-496.

12. Sinkovics JG (2007) Adult human sarcomas. I Basic Science. Expert Rev Anticancer Ther 7: 31-56.

13. Sinkovics JG (2007) Adult human sarcomas. II Medical Oncology. Expert Rev Anticancer Ther 7: 183-210.

14. Lichtman MA (2018) Historical landmarks in the understanding of the lymphomas. In Wiernik $\mathrm{PH}$, Neoplastic diseases of the blood. Springer Verlag, New York, 675-721.

15. Sinkovics JG Plager C, McMurtrey M, Romero JJ, Romsdahl MM (1977) Immunology and immunotherapy of human sarcomas. Immunotherapy of human cancer. $21^{\text {st }}$ annual clinical conference, 1976. The University of Texas System Cancer center M.D. Anderson Hospital and Tumor Institute, Year Book Medical Publisher, Chicago London, 361-410.

16. Sinkovics JG Plager C Papadopoulos N, McMurtrey M, Romero JJ, et al. (1978) Immunology and immunotherapy of human sarcomas. In: Immunotherapy of human cancer. $22^{\text {nd }}$ annual clinical conference, 1977. The University of Texas, M.D. Anderson Hospital and Tumor Institute, Raven Press, New York, 267-288. 